tion, the standard of which is intended to be that of the matriculation examination of an English university, and evidence of having passed such a matriculation examination, or other equivalent test, may be accepted by the College in lieu of its own entrance examination.

The one-year course is intended for those who require a less extensive acquaintance with the scientific aspects of agriculture, and the standard required from such entran is will be based mainly on a satisfactory school record indicating that they are able to profit by the instruction offered.

Special facilities will be afforded to officers selected for the tropical agricultural services, whether under government or otherwise, such as should enable them to obtain (through courses planned to meet individual needs) familiarity with the applications to tropical conditions of the principles they will have already acquired in Europe or elsewhere. It is difficult to exaggerate the value and importance of such training to men of this class before they proceed to take up the duties of the posts to which they may have been appointed. Hitherto there has existed a gap, largely unbridged, between the university at home and the work that awaits the scientific officer in his district, where the conditions that embrace his problems and affect their solution are so widely different from those within the range of his previous experience. The new College enables this hiatus to be short-circuited, and it should now be possible for a man in a few months to build effectively on his previous knowledge of principles. In short, he is now in a position to obtain easily, and under exceptionally favourable conditions, just that kind of wide outlook over, and reasonably intimate familiarity with, the material and environment of his prospective problems so necessary for ultimately attacking them with good prospects of success.

Perhaps, however, a word of caution may not be out of place here. In order to secure the best type of scientific officer, whether for government or for other services, it is fundamentally important that he should have received that kind of broad and thorough scientific training which only a first-rate and well-equipped university is in a position to give. It is not contended, and it must not be expected, that the training now available for scientific officers at the West Indian Agricultural College can replace this university type of education. What it can and will do is to utilise the results of that education, and to make it of more immediate and practical value. The motto of the College, Via colendi haud facilis, emphasises the difficulty of agricultural problems, and they are not going to be best attacked unless the best means are employed in the process. The combination of the home university and the tropical college unquestionably offers the best means at present in sight.

Finally, in its provision for research students the College is pursuing an excellent course. The West Indies, with the fine botanic gardens of Trinidad and Dominica, offer unrivalled opportunities to the botanist using Trinidad as a centre, and it would be difficult to find better facilities anywhere in the tropics. The relative freedom from noxious pests, the absence of the annoyance caused by the leeches of the eastern jungles, the variety and wealth of the vegetation, together with the striking ecological character it exhibits, combine to form a mort attractive prospect for any young man who desires ti secure that indispensable acquaintance with tropical vegetation without which no botanist can be said to be fully qualified to hold one of the more important chairs in the universities at home.

But it is, after all, by its success in promoting the welfare of agriculture, and of the industries that arise directly out of it, that the College will be finally judged. In this last connexion it is well to learn that technological courses are contemplated to prepare men to take their part in manufacturing processes. Some of these, for example sugar, are already of considerable importance in the West Indies and elsewhere. The establishment of a sugar school will constitute the first step in this direction, and gifts of up-to-date plant and machinery have already been generously promised by several engineering firms in Great Britain.

It will be obvious from the foregoing sketch-necessarily but an imperfect one-that the institution is making a good start. Sir Francis Watts and the little band of professors, all of whom have made their mark in various directions, will carry with them the best wishes of every one interested in the success of the great enterprise on which they have embarked.

\title{
The Flow of Steels at a Low Red Heat.
}

RECENT developments in chemical engineering have called for the provision of metallic containers capable of withstanding considerable stress at high temperatures and for long periods. The investigation of the mechanical properties of steels and alloys at these temperatures has accordingly become a matter of very direct practical importance. The existing literature of the subject almost invariably consists of graphs, in which tensile test results are plotted against the temperature at which the test was made, care being taken to eliminate the disturbing, but very important, factor of time, by carrying out each test under as nearly the same conditions as possible, the duration of each test being at most a few hours, with an actual loading time of a few minutes. It cannot fairly be claimed that such information gives more than a general indication of the relative ability of different materials to meet the working conditions usually encountered by the exhaust valve of an aeroengine or the retorts, catalyst tubes, etc., of the engineer. Certainly it does not enable a designer to construct a container which can be depended upon to maintain its shape indefinitely, at super-atmospheric temperatures when in a state of stress.

To remedy this defect in existing knowledge, Mr. J. H. Dickenson, of the Research Laboratories of Messrs. Vickers, Ltd., Sheffield, has carried out an experimental investigation, and communicated his results at the September meeting of the Iron and Steel Institute. His general conclusion is, that all the steels upon which he has worked behaved very much like highly viscous fluids at temperatures well below the 
critical range $\left(700^{\circ} \mathrm{C}\right.$.) and cannot be said to have any definite strength at a red heat, and that the property of principal importance to the engineer who wishes to subject highly heated steel to stress is the equivalent of the viscosity of a fluid. For the solution of a problem of immediate practical importance, he has ascertained for each of a number of steels the temperature at which the rate of flow does not exceed a very small and practically negligible amount under a uniform stress of 8.5 tons per square inch. The particular problem was the manufacture of large catalyst tubes for a synthetic ammonia process. These tubes were to be maintained at a temperature of about $600^{\circ} \mathrm{C}$. under an enormous internal pressure, a long life under these conditions being essential to the economic success of the process. After due consideration it was decided to make them of a nickel-chromium alloy which was known to possess high resistance to oxidation and deformation when under stress at high temperatures.

Laboratory tests were carried out on this alloy, on pure carbon steels, on a high chromium steel, and a high-speed steel. For details of the actual experiments the original paper must be consulted. It must be noted, however, that although the mechanical conditions chosen for the tests appear to have been considered with great care, there were considerable variations in the temperature of a given test-piece which amounted to as much as $\pm 25^{\circ} \mathrm{C}$. from a mean figure. Tests of two kinds were carried out: (a) those at constant load and constant temperatures, and $(b)$ those at constant load and uniformly rising temperature. The extension temperature diagrams of the $(b)$ series show that up to $400^{\circ} \mathrm{C}$. all the steels extended alike. Thereafter, however, the curves diverged, a considerable amount of flow taking place in each case, at temperatures well below that finally reached. The range of temperature investigated extended up to nearly $1000^{\circ} \mathrm{C}$.

The diagrams of the $(a)$ series present some remarkable results, of which perhaps the most striking was that of the test-piece of nickel-chromium alloy (Vikro), which extended continuously from the first day of loading (at $625^{\circ}$ C.) but only broke after 36 weeks.
The diagrams bring out well the enormous influence of time in determining the temperature up to which each type of steel can support a given load (in this case $8 \frac{1}{2}$ tons per square inch), and by implication a load which can be borne at any given temperature. As an example, a nickel-chromium alloy withstood the above stress under a rapidly applied load at $965^{\circ} \mathrm{C}$., whereas the same specimen cannot be expected to endure the same stress for considerable periods without suffering sensible deformation at a temperature exceeding $600^{\circ}$ C. Working conditions such as those outlined demand a knowledge of the latter figure.

Mr. Dickenson concludes from his tests that the extension and eventual rupture of the test-piece under unvarying load is due almost entirely to viscous flow. Whether plastic flow affects the shape of the curves, and if so, whether the data will prove sufficient to enable the plastic to be separated from the viscous flow, is a question to which he has not yet found an answer. His curves are also interesting for the light which they throw upon the differing degrees of resistance to mechanical deformation at high temperatures, which the various steels exhibit. Moreover, in selecting material for resistance to stress at these temperatures, the nature of the stressing action must be taken into account.

In the second half of his paper, consideration is given to the very important factor of resistance to "scaling" exhibited by steels at the temperatures in question. It has been known for some time that remarkable resistance to oxidation is offered by certain nickelchromium alloys, and, in a somewhat less degree, by high chromium steels. Mr. Dickenson has carried out systematic experiments on eight typical steels, in nine temperature ranges from $550^{\circ}-600^{\circ}$ up to $1075^{\circ}-1175^{\circ} \mathrm{C}$. The best results were given by a nickel-chromium alloy called "Vikro." Interesting photomicrographs are furnished, showing the varying character of the scale in the various alloys. Mr. Dickenson's research will be welcomed by chemical and metallurgical engineers, for it contains valuable information for which they have long been waiting. It is much to be hoped that he will see his way to continue his experiments.

\section{The Manufacture of Acids during the War. ${ }^{1}$}

\section{By Prof. T. M. Lowry, F.R.S.}

THE three technical reports before us deal with 1 the manufacture of sulphuric, nitric, and picric acids during the war. The reports are compiled on similar lines to those of the four earlier volumes which have already been reviewed in these columns (NATURE, April 29, I922, p. 54I); and since the methods and workmanship of Mr. W. Macnab are now well known, it is not necessary to describe in detail the type of information which they contain. It may, however, be of interest to review briefly the general situation as

${ }^{1}$ Ministry of Munitions and Department of Scientific and Industrial Research. Technical Records of Explosives Supply, 1915-rgr8. No. 5: Research. Technical Records of Explosives Supply, 19r5-r918. No. 5:
"Manufacture of Sulphuric Acid by Contact Process." Pp. vi + 128 +plates.

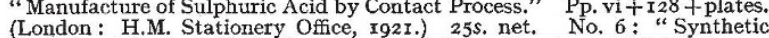
(London : H.M. Stationery Office, 1921.) 25s. net. No. 6: "Synthetic Phenol and Picric Acid." Pp. vi +97 tplates. (London : H.M. Stationery
Office, 192x.) I5s. net. No. 7 : "Manufacture of Nitric Acid from Nitre Office, I92x.) I5s. net. No. 7. "Manufacture of Nitric Acid from Nitre
and Sulphuric Acid." Pp. vi +86. (London : H.M. Stationery Office, r922.) as. $6 d$. net.

$$
\text { NO. } 277 \mathrm{I} \text {, VOL. I IO] }
$$

regards supplies of acids which had to be met by the Department of Explosives Supply, and the way in which the problem was solved by the workers of that Department, as disclosed in these three reports.

\section{Nitric ACID.}

Although oxidised nitrogen was the key of the supply-problem in explosives-both propellant and $\mathrm{H}: \mathrm{E}$. (just as chlorine was the basis of the supplyproblem in gas-warfare in its successive phases of chlorine, phosgene, $\mathrm{CCl}_{3} \mathrm{NO}_{2}, \quad \mathrm{~S}\left(\mathrm{C}_{2} \mathrm{H}_{4} \mathrm{Cl}\right)_{2}$, or mustard gas, etc.) - the report on the manufacture of nitric acid is undoubtedly the least important of these three, since it is much to be hoped that this country will never again be dependent on overseas 